Letrônica, Porto Alegre, v. 7, n. 1, p. 435-451, jan./jun., 2014

\title{
NARRATIVAS DA DIÁSPORA FEMININA CONTEMPORÂNEA: UMA LEITURA DE ALGUM LUGAR, DE PALOMA VIDAL
}

\author{
NARRATIVES OF CONTEMPORARY FEMALE DIASPORA: \\ AN ANALYSIS OF ALGUM LUGAR, BY PALOMA VIDAL
}

\author{
Joyce Luciane Correia Muzi* \\ Wilma dos Santos Coqueiro** \\ Lúcia Osana Zolin***
}

\begin{abstract}
Resumo: Paloma Vidal, em seu primeiro romance Algum lugar (2009), nos apresenta uma "escrita do eu" que possibilita um passeio por algumas grandes metrópoles modernas ao mesmo tempo em que percorremos as páginas de um diário de uma jovem estudante e professora. Seu texto, marcado pelas referências a obras e autores canônicos, é baseado em reminiscências que fazem da obra uma tentativa de se encontrar e se identificar com espaços, pessoas e outros textos, no passado e no presente. Além disso, a escritora de nacionalidade argentina, mas residente no Brasil desde a infância, problematiza no romance a condição de desterritorialização do migrante que, ao estar situado em outro país, enfrenta a solidão e as consequências da diáspora. 0 objetivo deste artigo é refletir sobre esse tema que ocupa um lugar central na cena contemporânea, provocada pela mundialização da cultura e que está em foco em obras literárias como a de Paloma Vidal. As análises respaldam-se em referências oriundas, sobretudo, dos Estudos Culturais como Edward Said (2003), Zygmunt Bauman $(1998,2001)$ e Stuart Hall (2003).

Palavras-chave: Narrativas da Diáspora; Paloma Vidal; Sociedade Globalizada; Exílio.
\end{abstract}

\begin{abstract}
Paloma Vidal, in her first novel, Algum lugar (2009), presents a "writing of the self" that enables a stroll around some major modern metropolises while we travel along the pages of a young student and teacher's diary. Her text, marked by references to canonical works and authors, is based on reminiscences that turn the work into an attempt to find and identify oneself with spaces, people and other texts, in the past and present. Moreover, the Argentine writer, who lives in Brazil since her childhood, discusses in her novel the deterritorialization condition of the migrant, who, by living in another country, faces the loneliness and the consequences of diaspora. This article aims at building a reflection on such topic, which occupies a central place in the current scene, caused by the globalization of culture that appears in literary works such as Paloma Vidal's. The analyzes are supported by references derived mainly from Cultural Studies, such as Edward Said (2003), Zygmunt Bauman $(1998,2001)$ and Stuart Hall $(2003)$.
\end{abstract}

Keywords: Diaspora Narratives; Paloma Vidal; Globalized Society; Exile.

\footnotetext{
* Doutoranda em Letras pela Universidade Estadual de Maringá. Professora do Instituto Federal do Paraná, Campus Curitiba. E-mail: joyce.muzi@ifpr.edu.br

** Doutoranda em Letras pela Universidade Estadual de Maringá. Professora da Universidade Estadual do Paraná, Campus Campo Mourão. E-mail: wilmacoqueiro@ibest.com.br

${ }^{* * *}$ Doutora em Letras pela Universidade Estadual Paulista Júlio de Mesquita Filho. Professora Associada da Universidade Estadual de Maringá. E-mail: luciazolin@yahoo.com.br
} 
Algum lugar (2009), primeiro romance da escritora Paloma Vidal, apresenta a história de uma mulher, cujo nome não sabemos, contada por ela mesma, sobre sua vida a partir do momento que se muda para Los Angeles, com seu então companheiro, para escrever uma tese de doutorado. 0 romance se estrutura como um diário, cujos fatos são narrados em ordem cronológica, ainda que não apareçam inscrições de datas. Quase sempre em primeira pessoa, estes fragmentos justapostos intercalam-se com flashbacks e intervenções em terceira pessoa, por meio dos quais conhecemos, por exemplo, aspectos ou fatos do seu passado; além disso, há ainda anotações em segunda pessoa, as quais se limitam a descrever e comentar seus próprios sonhos.

Ainda em relação à estrutura, este "diário" está dividido em três partes: na primeira, mais longa, intitulada "Los Angeles", a protagonista narra o período que viveu fora do Brasil; na segunda, intitulada "Rio de Janeiro", ela narra seu retorno ao Brasil e na terceira e última, intitulada "Los Angeles" há uma quebra no padrão anterior, pois "Los Angeles" nesse caso não é a cidade, mas um espaço, um estabelecimento num outro país que se relaciona com o enredo.

A primeira parte, "Los Angeles", é composta por três capítulos, já as segunda e terceira partes constituem um grande bloco. Os capítulos e blocos são formados por sequências narrativas colocadas uma após a outra, mas que quase sempre dizem respeito a fatos, ou dias diferentes, se os tomarmos como um diário. Graficamente, portanto, há espaços vazios entre cada um desses dias ou fatos narrados.

No interior do próprio romance, numa espécie de sugestão metalinguística, o/a leitor/a se depara com pistas a respeito da escolha por esta estrutura narrativa inspirada na estrutura de Rua de mão única (1987) de Walter Benjamin (1892-1940). Apesar de pouco convencional para um livro de filosofia, essa coletânea de aforismos e de fragmentos na obra do escritor alemão tem por objetivo refletir acerca de seu impasse frente à "escrita da cidade", entendida como um contexto de alienação alarmante, repleta de pequenos textos como outdoors, tabuletas, anúncios, folhetos, manchetes, luminosos, cartazes, monumentos, praças, galerias, etc., os quais impõem a distração e a aproximação acrítica como modo de leitura, como também uma forma de escrita que, num certo sentido, relativiza o valor da cultura literária, baseada no livro. Esta não é a única semelhança entre as obras. Assim como Benjamin intercala a 
descrição de sonhos aos fragmentos, em Algum lugar também os sonhos compõem a narrativa. No livro de Paloma Vidal, vinte e quatro são os sonhos no total, e eles surgem nas três partes do livro, escritos na segunda pessoa: "Você sonha que acabou de chegar em Los Angeles..." (VIDAL, 2009, p. 23. Sonho 1); "Você sonha com o seu irmão..." (VIDAL, 2009, p. 26. Sonho 2); "Você sonha que está num quarto com um homem que não conhece. É só disso que se lembra” (VIDAL, 2009, p. 78. Sonho 10).

Esta hipótese de que Rua de mão única serviu como obra "inspiradora" está, também, na referência à introdução de Susan Sontag (1933-2004), ao texto benjaminiano: a crítica e escritora estadunidense sugere que o/a leitor/a está prestes a ler "um texto mais subjetivo do que crítico, ou melhor, um texto em que a subjetividade e crítica são uma coisa só porque se entende que a vida e o trabalho são uma coisa só" (VIDAL, 2009, p. 25). A subjetividade é, certamente, uma das características primordiais do romance da escritora argentino-brasileira.

Do mesmo modo, a própria filosofia que alicerça a construção de Algum lugar guarda íntimas relações com o modo como Benjamin (1986), ao decretar a morte da arte de narrar, concebe o romance: uma mera forma de comunicação, um instrumento do capitalismo, pautado na experiência.

Porém, segundo Beatriz Resende (2011), é, paradoxalmente, na narrativa tradicional que Paloma Vidal vai buscar o aspecto mais esmerado em seu primeiro romance: a reminiscência. E a pesquisadora explica como a autora consegue isso:

\footnotetext{
O modelo de narrativa segue as possibilidades diversas de escrita íntima. 0 diário de viagem ou aquele mais privado onde seu autor registra um pensamento, uma impressão, um sentimento inexplicável, uma frase única que precisa ser registrada para reflexão futura: "M trocou o dia pela noite: janta diariamente às 3 da manhã". Ou o registro de um sonhador separado do corpo que adormeceu: "Você sonha mais uma vez com o homem desconhecido..." E diários de leituras, como o registro da introdução de Susan Sontag a Rua de mão única, onde Benjamin menciona os inúmeros cadernos, cartas, diários. "Tudo vira escrita, até os sonhos, uma escrita capaz de condensar a experiência". A reminiscência aproxima, definitivamente, o narrador do leitor, já que uma das propriedades do narrador é poder narrar, com dignidade, a própria vida. (RESENDE, 2011, s.p.)
}

Nesse sentido, a forma é aspecto fundamental para a compreensão do romance de Paloma Vidal. Como está interessada em registrar suas recordações, a narrativa se organiza em uma constelação de fragmentos, narrados em primeira, segunda e terceira 
pessoas, que sugerem a estrutura de um diário, incidindo assim em um tom altamente confessional.

O aumento de narrativas de cunho testemunhal ou memorialista surge imperativo diante da fluidez e nomadismo do mundo contemporâneo, no qual se busca reconstruir a trajetória individual, e muitas vezes de uma coletividade, por meio do resgate de imagens do passado e até mesmo de meros fragmentos, que ao serem colados, constituem um mosaico representativo da nossa época de incertezas e precariedades. Para Riaudel (2009), essas obras constituem-se como "ficções, portanto, com suas pregas, seus meandros, reciclando, contudo, as trajetórias individuais" (RIAUDEL, 2009, p. 252).

A narradora de Algum Lugar busca plasmar a experiência vivida por meio da única faculdade que tem qualidade de permanência que é a memória, tentando, inutilmente, deter o tempo que passa e as perdas inerentes a ele. Para Riaudel (2009), esse caráter retrospectivo da "escrita do eu" propicia um desdobramento do tempo, unindo o plano pretérito dos acontecimentos que estão sendo narrados com o presente da enunciação. A unificação da diégese, mesmo com os riscos previstos de uma narrativa parcial, ocorre por meio da subjetividade central. De certo modo, é o que atesta Remédios (1997), ao descrever a autobiografia, mas cujas considerações servem para as narrativas memorialistas como um todo: "Parece que a literatura confessional é aquela que mais se aproxima do leitor porque fala de um eu, de uma pessoa viva que ali se encontra diante do leitor, desnuda sua vida, estabelecendo-se, então, uma perfeita união entre autor e leitor" (REMÉDIOS, 1997, p. 9).

Pode-se dizer, então, que tal como um/a leitor/a percorre as páginas de uma obra em busca de algo que lhe desperte interesse, a personagem de Algum lugar percorre sua memória, e, tal como numa rua de mão única, recupera aquilo que nela se conserva, independente do que seja. Assim como o livro de Benjamin, a narrativa está imersa na subjetividade da vida, cabendo à narradora, segundo Resende (2011), contá-la com dignidade.

Como tem sido bastante comum na literatura contemporânea, sobretudo a partir dos últimos anos do século XX, o romance de Paloma Vidal tematiza a questão da imigração, mas não mais do imigrante estrangeiro que chega ao Brasil para fazer a América, como o patriarca espanhol Madruga que protagoniza A República dos Sonhos, 
publicado em 1984, por Nélida Piñon, ou as personagens de ascendência libanesa, como a matriarca Emilie que integra o romance Relato de um certo Oriente, publicado em 1989, por Milton Hatoum. Autoras como Paloma Vidal e Adriana Lisboa, entre outras, problematizam a emigração do brasileiro para outros países, nem sempre por motivos econômicos e políticos, mas também por razões pessoais ou educacionais.

Almeida (2010) relaciona esse aspecto intimista presente na obra de várias escritoras contemporâneas com a inserção feminina no novo contexto social globalizado e cosmopolita, cujo pertencimento se revela sempre temporário. Segundo a autora, nesse contexto, são as identidades híbridas e afiliações transitórias que definem os sujeitos, em especial, os femininos.

No caso das escritoras migrantes de autoria feminina que têm marcado a cena contemporânea, a mobilidade cultural muitas vezes não é somente parte do mundo ficcional descrito pelas autoras, mas também do papel ativo que assumem como intelectuais contemporâneas, muitas vezes como intelectuais de uma denominada nova diáspora. (SPIVAK, 1996 apud ALMEIDA, 2010, p. 13)

Nesse ponto, são importantes as considerações do intelectual, ativista e crítico literário palestino Edward Said (1935-2003), que se tornou um dos expoentes dos estudos pós-coloniais, acerca desse gênero da literatura dos séculos XX e XXI, chamada por ele de "extraterritorial", que tem como marca o fato de ser feita por exilados e sobre exilados. Segundo ele, "poetas e escritores exilados conferem dignidade a uma condição criada para negar a dignidade - e a identidade das pessoas" (SAID, 2003, p. 48).

Para Chiarelli (2007), verifica-se na atualidade - a partir do boom dos estudos culturais que focalizam questões como raça, etnia, gênero e sexualidade - uma reversão do olhar em relação aos grupos outrora mantidos à margem da cultura literária. Desse modo, o Outro, excluído ou reprimido historicamente, passa a ocupar um novo patamar na representação literária, "em que outros lugares de fala começaram a emergir" (CHIARELLI, 2007, p. 24). É nesse caso, que a literatura, a partir da perspectiva póscolonial, passa a ter representações de mulheres, negros, índios, homossexuais e também dos imigrantes/emigrantes. Para Chiarelli, a partir do momento que outros discursos entram em cena, na defesa legítima dos espaços das minorias, "o estrangeiro desperta interesse, transforma-se novamente em tema, torna-se alvo de debates e polêmicas contemporâneas" (CHIARELLI, 2007, p. 24). 
Tendo em vista essa perspectiva, é de crucial importância refletir sobre o modo como a autora contemporânea, Paloma Vidal - também ela exilada, nascida na Argentina e habitante não naturalizada do Brasil, desde os dois anos de idade, - problematiza em seu romance a condição do emigrante e a hibridização cultural, tão características da contemporaneidade.

De forma resumida, podemos dizer que a autora graduou-se em Letras, pela Universidade Federal do Rio de Janeiro, em 1999, concluiu o Doutorado em 2006, pela Pontifícia Universidade Católica do Rio de Janeiro, e, desde 2009, leciona na Universidade Federal de São Paulo, na área de Teoria Literária. 0 seu primeiro romance Algum Lugar, publicado em 2009, foi escrito paralelamente à tese de doutoramento, entre os anos de 2002 e 2006, quando a autora passou parte desse tempo em Los Angeles, nos Estados Unidos.

Esta temática da viagem é inserida no romance, uma vez que, assim como a autora, a narradora não-nomeada de Algum Lugar também sofre esse deslocamento em função de estar em Los Angeles para escrever a tese de doutoramento. Assim, muitos temas abordados em sua obra como o exílio, a viagem, o hibridismo cultural, são oriundos de sua biografia, uma vez que a própria autora tem dificuldade em se definir como argentina ou brasileira, por isso nunca se naturalizou brasileira, preferindo transitar por duas culturas diversas. Ao ser questionada se a literatura é uma experiência catártica, ela afirma que a escrita tem essa capacidade de trazer à tona coisas sobre nós. E mais adiante, ela aborda uma problemática que está muito entranhada na protagonista do romance em análise: a questão da identidade da personagem migrante que pertence a dois lugares diferentes e, ao mesmo tempo, a nenhum deles:

Essa é uma outra pergunta que eu não tenho como responder. Acho que nunca terei. Eu sou argentina e brasileira, ou brasileira e argentina, e acho que posso ser de muitas cidades, posso me sentir bem em muitas cidades, encontrar uma cotidianidade minha nelas, mas, ao mesmo tempo, sempre estou pensando em me mudar, em como seria morar em outro lugar, porque também sempre tenho a impressão de não pertencer completamente a cidade nenhuma. (GHETI, 2012, s.p.)

A propósito dessa fala de Paloma Vidal, é relevante mencionar que Maffesoli (2001) destaca o fato de que atualmente tem se difundido a palavra de ordem "guardar distância" em relação aos diversos nacionalismos e às adesões partidárias. Daí decorre a 
rejeição de muitos escritores em relação às ideologias e nacionalismos. Para ele, "o fato de não se enraizar, de estar à vontade em múltiplas culturas, é uma postura intelectual e existencial muito espalhada hoje em dia" (MAFFESOLI, 2001, p. 141).

Ao alçar como protagonista de seu romance uma professora brasileira deslocada de seu país e de sua cultura, tentando se adaptar a um meio hostil e indiferente, enquanto frequenta uma universidade em Los Angeles, a narrativa de Vidal potencializa o modo de pensar a identidade nacional, a partir da experiência traumática da diáspora.

A personagem é uma brasileira, filha de mãe argentina (do pai, pouco citado, não sabemos muito). Ela vai viver por um tempo em Los Angeles, enquanto ela e o companheiro escrevem suas respectivas teses de doutorado e frequentam aulas em uma universidade.

Para se compreender a problemática da personagem, torna-se relevante abordar, mesmo que de forma rápida, as distinções propostas por Said (2003) entre exilados, refugiados, expatriados e imigrados, embora, na sua concepção, toda pessoa que esteja impedida de voltar para casa, por quaisquer motivos, seja, de certa forma, um exilado. Contudo, a rigor do termo, o exilado seria aquele que fora banido da pátria, condenado a uma vida infeliz e solitária em outro país. Os refugiados, criação do século XX, são os que emigram, geralmente em "rebanhos", por conflitos políticos, como guerras, genocídios, fome e outras catástrofes, e ficam à mercê da ajuda internacional. Os expatriados são os que saem de seus países por motivos pessoais, geralmente de forma voluntária - como os escritores americanos Hemingway e Fitzgerald, citados por Said, - mas que podem sentir a mesma solidão que um exilado. E finalmente, os emigrados, para Said, desfrutam de uma situação ambígua, que prevê sempre uma escolha no ato de emigrar.

Desse modo, fica evidente que nem sempre é possível definir a fronteira tênue que separa uns dos outros. Para o autor, "vistos com a indiferença que caracteriza o ponto de vista político dos deslocamentos maciços da atualidade, os exilados individuais nos forçam a reconhecer o destino trágico da falta de lar num mundo necessariamente implacável" (SAID, 2003, p. 56).

Nessa condição traumática de exilada, ou expatriada, uma das questões apresentadas no romance é a frustrante necessidade de identificação da protagonista com os lugares por onde passa. Com efeito, o primeiro cenário apresentado, o saguão do aeroporto de Los Angeles representa, metonimicamente, a condição da narradora, ao 
longo do romance, sempre em busca de um pertencimento. Para Bauman (2001) a modernidade líquida e para Augé (2005) a supermodernidade, como formas de referência à contemporaneidade, são produtoras de não-lugares. Lugares como rodoviárias, aeroportos, autoestradas, quartos anônimos de hotel, entre outros, são, para Bauman, espaços destituídos "das expressões simbólicas de identidade, relações e história" (2001, p. 120). Augé acrescenta que esses pontos de trânsito se constituem em ocupações precárias e provisórias que, por sua vez, constituem "um mundo assim prometido à individualidade solitária, à passagem, ao provisório, ao efêmero" (2005, p. 74).

A solidão como experiência particular do e no não-lugar, como nos ensina Augé (2005), é o que de fato a incomoda quando ocorre um contato com um guarda no aeroporto: "onde há um café? Não há nada por aqui, o homem responde sorrindo. E cadeiras? Também não há" (VIDAL, 2009, p. 15). A impressão que fica à personagem é de que o lugar fora construído para expulsar as pessoas em trânsito e isso a atormenta, uma vez que está sozinha em um país estranho, em meio a uma multidão. De acordo com Bauman, o vazio do não-lugar está relacionado ao olhar de cada um ao definir como vazios "os lugares em que não se entra e onde se sentiria perdido e vulnerável, surpreendido e um tanto atemorizado pela presença de humanos" (BAUMAN, 2001, p. 122), que é o que ocorre com a protagonista no aeroporto, nas ruas da cidade, em locais públicos.

Outro aspecto da obra que se revela como cartografia identitária do não-lugar é o fato de a protagonista preferir o transporte público para transitar com o objetivo de estabelecer relações com a cidade. Para Bauman, esses espaços de passagem, que são desenhados para serem circundados e não atravessados, são marcados pela presença apenas física e socialmente indiferente dos estranhos uma vez que são "anuladas" as suas subjetividades. Isso porque "os residentes temporários dos não-lugares são possivelmente diferentes, cada variedade com seus próprios hábitos e expectativas; e o truque é fazer com que isso seja irrelevante durante sua estadia" (BAUMAN, 2001, p. 119). Na narrativa de Vidal isso se evidencia no insucesso no estabelecimento de relações da personagem ao andar de ônibus, fazendo com que ela se conforme com a 
posição de flanêur ${ }^{1}$ ao parar e observar os adolescentes rindo, a mendiga que monologa a respeito de sua condição de mulher velha e do preço da passagem do ônibus, a ação/reação do motorista. A sua convicção de que "enquanto passa pela janela a paisagem urbana, que vou aprendendo a reconhecer, faço parte desse microcosmo provisório como estátua viva" (VIDAL, 2009, p. 29), provoca a ilusão de que seu objetivo - fazer parte de uma comunidade - se concretiza.

\begin{abstract}
Percebo que estou querendo criar para mim um circuito doméstico na cidade, contrariando a evidência de que o meu bairro não é um bairro. Comemoro cada nova descoberta como uma pequena vitória contra a dispersão da cidade. Já sei onde encontrar uma tinturaria, um mecânico, uma relojoaria; [...] Uma loja de fantasias? Para que você quer uma loja de fantasias?, M pergunta. Não importa. o que importa é a descoberta, como se a promessa de uma necessidade sanada pudesse me resgatar provisoriamente de meu estado de isolamento. Se precisar, já sei onde encontrar. É um caminho que se desenha entre dois pontos que antes não tinham conexão alguma. (VIDAL, 2009, p. 32. Grifos nossos.)
\end{abstract}

Bauman (2001) aborda essa capacidade das sociedades contemporâneas - ou líquido-modernas, na sua concepção - de criar e anular os estranhos. Desse modo, se o contato físico com estranhos não pode ser evitado, pelo menos ele pode ser despido da ameaça de diálogo e interação. E acrescenta que isso faz com que eles possam ser vistos, mas não ouvidos. Se os lugares públicos permitem que "lavemos nossas mãos de qualquer intercâmbio com os estranhos a nossa volta e evitemos o comércio arriscado, a comunicação difícil, a negociação enervante e as concessões irritantes" (BAUMAN, 2002, p. 122), a necessidade da protagonista de convivência leva a forçar uma comunhão, mesmo se dando conta de que a cidade não foi feita para ser habitada.

...em Los Angeles as avenidas não são exatamente vias de transporte; para se locomover, existem as freeways [...] com suas entradas e saídas que guardam uma relação apenas tangencial com o desenho quadriculado, remanescente de uma cidade em que a calçada ainda fazia algum sentido. (VIDAL, 2009, p. 19)

Isso remete à descrição de Berman (2007) a respeito da arquitetura moderna das grandes cidades que não teriam sido concebidas para atender às necessidades de convivência e interação humana. Desse modo, a protagonista se vê imersa nessa lógica americana apontada por Berman: as freeways, comuns nos EUA entre as décadas de

\footnotetext{
1 "O homem da multidão" de Edgar Allan Poe é considerado um marco da literatura flanêur do século XIX. Walter Benjamin o descreve como um produto da vida moderna e da Revolução Industrial. Podemos traduzir o termo como andarilho (Dicionário Aurélio Eletrônico Século XXI).
} 
1920-60, tornam-se o símbolo do progresso, mas também são responsáveis pela destruição de muitos quarteirões comerciais e pelo isolamento forçado. A crítica de Berman a essa "devastação" que as vias expressas causaram no país aponta para o que a personagem vê:

Quando lhe perguntaram [a Robert Moses], logo após o término da CrossBronx, se as vias expressas urbanas como aquela não colocavam problemas humanos especiais, ele replicou impaciente que "quase não há contratempos em relação a isso. Há um pouco de incômodo e mesmo este é exagerado". (BERMAN, 2007, p. 344)

A cidade de Los Angeles, imapeável e inconquistável, acaba por se configurar como um obstáculo à adaptação da personagem, que constantemente se questiona: "Você queria realmente estar aqui?" (VIDAL, 2009, p. 18). E mais tarde, ela salienta seu estranhamento e inadaptação ao confessar que a cidade lhe transmitia "uma sensação de estarmos fora do tempo, de eternidade, uma sensação de onipotência que tem seu contraponto no terror de que um dia a cidade possa sumir do mapa" (VIDAL, 2009, p. 56).

O crítico jamaicano Stuart Hall (1932-2014), que faleceu recentemente, foi um dos grandes teóricos dos Estudos Culturais. Ao pensar a diáspora, a partir do contexto das sociedades caribenhas, em época de globalização e dissolução das fronteiras nacionais, ele sublinha que "a migração se tornou o grande evento histórico-mundial da Modernidade Tardia, a experiência diaspórica se tornou uma experiência pós-moderna clássica" (HALL, 2003, p. 16). As considerações de Hall são fundamentais para se compreender como a diáspora tornou-se um tema central da contemporaneidade, denominada por ele de Modernidade Tardia. Seria essa modernidade a produtora dos personagens desterritorializados que frequentam a literatura contemporânea, profundamente marcados pelo nomadismo, a errância e a expatriação.

Na concepção de Hall, a diáspora, que tem como causas principais a pobreza, o subdesenvolvimento e a falta de oportunidades, "está fundada sobre a construção de uma fronteira de exclusão do outro" (HALL, 2003, p. 33), tornando as identidades múltiplas ao haver uma ruptura dos elos naturais pela experiência do deslocamento.

Por isso, a personagem de Vidal, empaticamente, se une ao temor coletivo de perda de referência de um lugar que ela já está quase chamando de casa. Isso tem justificativa, de acordo com Bauman (1998), para quem os habitantes nômades buscam 
se fixar. Por isso, a crença utópica de que "além da curva, existe, deve existir, tem que existir uma terra hospitaleira em que se fixar" (BAUMAN, 1998, p. 92), mesmo que surjam sempre novas curvas, novas frustrações como também novas esperanças.

A personagem, movida pelo desejo de conquista da cidade, decide se aventurar em uma ida ao museu. Quando a mãe lhe telefona com essa sugestão, ela desconfia da impossibilidade de vencer as distâncias de uma cidade que definitivamente não teria sido feita para pessoas, mas sim para veículos, ao argumentar que "as ruas desertas intimidam, como se ao andar estivéssemos fazendo algo proibido" (VIDAL, 2009, p. 36). Mesmo descrente da possibilidade de convivência, ela decide ir ao museu, buscando passar-se despercebida, integrada à lógica da cidade. Porém, a ida ao museu torna-se mais difícil do que aparentava, propiciando a sensação angustiante do fracasso.

...tenho certeza de estar colocando a mim mesma num desafio inútil, personificando a cidade, transformando-a num ser que preciso conquistar, fixando-a na imagem de um modo de vida ao qual eu deveria resistir, apesar de admitir que sou totalmente capaz de me adaptar a ele. (VIDAL, 2009, p. 39)

Conforme relata a protagonista, a caminhada pela "405, sem sombra, sem calçada, com os carros passando a uma proximidade alarmante" (VIDAL, 2009, p. 39), remete às considerações de Bauman sobre esses espaços das sociedades contemporâneas. Segundo ele, muitos desses espaços públicos "são imponentes e inacessíveis aos olhos" (BAUMAN, 2001, p. 113). Berman também faz referência a esses espaços vazios e inabitáveis, ao relatar sua passagem por Brasília, uma cidade concebida de forma moderna, ao expressar que "a sensação geral que se tem - confirmada por todos os brasileiros que conheci - é a de enormes espaços vazios em que o indivíduo se sente perdido, tão sozinho quanto um homem na lua" (BERMAN, 2007, p. 13).

Essa saída a pé acaba por fazer a personagem admitir que já estava conformada com aquele modo de vida, no qual as pessoas, fechadas em seu mundo próprio, se locomoviam com objetivos determinados. Mesmo que tenha tentado resistir a esse anonimato imposto, ela já fazia parte da cidade e de sua lógica inabitada/inabitável. Permanecer os dias fechada no apartamento ou na salinha do subsolo, fazendo o percurso casa/universidade sem espaços para imprevistos, se reflete na ausência de uma vida social e, consequentemente, na superficialidade das relações com outras pessoas. 
Em outra oportunidade, ao receber um convite para participar de um curso em uma universidade, a personagem se aproveita da ocasião para explorar outro lado da cidade. Nesse caso, ela precisa descobrir como chegar até lá. Para ela, é evidente que a rota, mesmo que pareça fácil, provocaria espanto em qualquer pessoa. Contudo, para ela não provoca nem espanto nem interesse, uma vez que nesse outro lado da cidade de Los Angeles "não há charme boêmio nem glamour cinematográfico. A praia está longe. Tudo é muito plano: casas, lojas, galpões. Aqui e ali, uma palmeira. Pouca gente na rua" (VIDAL, 2009, p. 91).

Diante desse cenário, torna-se inevitável a comparação da narradora entre a cidade vista agora com aquela descrita, setenta anos antes, por John Fante (1909-1983), na obra Pergunte ao ó́ $^{2}$, de 1939. Ao refletir que a arquitetura da cidade parece não ter idade, ela rememora: "Lembro de ter uma sensação esquisita ao ler Pergunte ao pó, porque o livro é de 1939, mas tem uma atualidade geográfica que seria impossível em outros lugares, como se Los Angeles há setenta anos já fosse essencialmente a cidade de agora" (VIDAL, 2009, p. 91).

A memória da cidade de Los Angeles, povoada por imigrantes da obra de John Fante, remete a uma situação da qual ela não sabe se faz parte. Com efeito, o que mais se destaca nessa referência é o trecho transcrito pela narradora, extraído das primeiras páginas do romance citado: “'Los Angeles, dê me um pouco de você! Los Angeles, venha a mim do jeito que eu vim a você' - Bandini implorava e a cidade até certo ponto se entregava" (VIDAL, 2009, p. 92). Ao repetir a mesma frase dita por outro personagem ficcional, a protagonista de Algum Lugar está expressando a mesma angústia diante do sentimento de desterritorialização imposto por essa sociedade líquido-moderna.

Para Augé (2005), uma das facetas do não-lugar seria a criação de tensão solitária. Segundo ele, o estrangeiro perdido num país só consegue encontrar o anonimato e "é no anonimato do não lugar que se experimenta solitariamente a comunhão dos destinos humanos" (AUGÉ, 2005, p. 110). Por isso a conclusão da narradora de que Los Angeles era somente "um pano de fundo. É quase como se não existisse e seu apagamento nos ampara na tarefa que viemos cumprir" (VIDAL, 2009, p.

\footnotetext{
${ }^{2} \mathrm{Na}$ obra, de 1939, considerada a mais popular do autor, Arturo Bandini, o protagonista imigrante, é um jovem que pretende se tornar escritor, mas que se sente excluído da sociedade. A cidade escolhida para sua empreitada é Los Angeles. Se é possível a intertextualidade, o personagem da obra de Fante, assim como a nossa protagonista, é um imigrante; ele pretende ser escritor e ela vai manifestar o desejo de escrever à medida que a narrativa avança.
} 
27), mesmo que sinta uma nostalgia antecipada ao vislumbrar, de forma hipotética, a saída da cidade: "Porque se me perguntassem se gosto da cidade, não saberia o que responder e assim ela nunca seria minha" (VIDAL, 2009, p. 122).

De certo modo, as dúvidas e os questionamentos da personagem apontam para essa forma de sobreviver de forma isolada. Em contraposição a essa posição de conformismo, seu companheiro M acaba por demonstrar a insatisfação e o desconforto com a vida exterior que o atinge e o leva a passar os dias enclausurado no apartamento, passando a não interagir nem mesmo com a protagonista. Em trechos como "Não percebi imediatamente que M estava transformando nosso apartamento num refúgio" (VIDAL, 2009, p. 66) e "M trocou o dia pela noite: janta diariamente às 3 da manhã" (VIDAL, 2009, p. 86) evidenciam-se o modo como a diferença de hábitos impõe uma grande distância temporal e afetiva entre o casal, mesmo que continuem, por um tempo, a dividirem o mesmo espaço.

Said (2003) aborda essa vivência do exilado, marcada por um sentimento de perda terminal, ao enfatizar que o isolamento e o deslocamento podem produzir um tipo de masoquismo narcisista capaz de resistir ao processo de aculturação e comunicabilidade. $\mathrm{O}$ autor acrescenta ainda que "nesse ponto extremo, o exilado pode fazer um fetiche, uma prática que o distancie de quaisquer conexões ou compromissos" (SAID, 2003, p. 57). Isso é evidenciado na obra nos modos diferentes de reação dos personagens em relação à cidade. Ao mesmo tempo que a protagonista busca uma adaptação, mesmo que forçada, com a cidade, seu companheiro se retrai na subjetividade e no isolamento. Said salienta ainda que essa postura é extremamente negativa uma vez que "viver como se tudo a sua volta fosse temporário e talvez trivial é cair na armadilha do cinismo petulante bem como da falta lamuriosa de amor" (SAID, 2003, p. 57).

A partida de M “em uma manhã ensolarada de novembro" (VIDAL, 2009, p. 101) é o desfecho previsível de uma relação atravessada pela força centrífuga de uma cidade que os aprisiona, faz com que a nova fase na vida da protagonista seja marcada pela solidão e pelo abandono: "Na ausência dele a memória me atormenta. É como se o passado tivesse ganhado existência de repente, como se Los Angeles, que até esse momento havia sido puro presente, fosse agora parte de um tempo perdido" (VIDAL, 2009, p. 101-102). 
Diante da dor mutiladora da separação, ainda que temporária, a personagem mergulha nos sentimentos de solidão e abandono, sentindo, mais do que nunca, o sentimento de exílio e desamparo diante de um mundo que para ela se mostra cada vez mais adverso. Por isso, o exílio torna-se "terrível de experienciar" (SAID, 2003, p. 46). Esse momento de fratura cinde a existência da personagem, tornando impossível sua permanência nos Estados Unidos.

0 retorno ao Rio de Janeiro, que se torna definitivo devido à descoberta de uma gravidez não planejada, faz com que ela se sinta em um lugar mais familiar, sobre o qual ela tem referências, e conquiste uma nova independência. Contudo, mesmo estando nesse lugar familiar, permanece o sentimento de distanciamento, isso porque "andava então pelas ruas como se nelas fosse recuperar algo que se perdeu" (VIDAL, 2009, p. 126). Mesmo sabendo que a cidade era a mesma, permanece a busca por "uma justificativa para a inadequação do retorno" (VIDAL, 2009, p. 127). Seja enquanto viveu em Los Angeles, quanto na volta ao Rio de Janeiro, as comparações e sobreposições eram inevitáveis: "me sinto tentada a sobrepor uma geografia sobre a outra como para medir o grau de meu deslocamento ou forçar uma adaptação necessária" (VIDAL, 2009, p. 29).

Nos sonhos, com Los Angeles ou com o Rio de Janeiro, muitas vezes as cidades não são elas mesmas. Elas podem ter se transformado em cenário futurista, em sombra ou num deserto; mas elas sempre estão lá como um pano de fundo à espreita. Existiriam elas somente para isso: para ser um simples cenário, inerte, por onde passam pessoas? $\mathrm{Ou}$ nem para isso, se lembramos da referência de Berman ao Palácio de Cristal, imaginado por Dostoievski, que pode ser comparado à Brasília de Lúcio Costa e Oscar Niemeyer, a Los Angeles ou a qualquer outra cidade moderna: elas não deixam a seus habitantes “'nada mais a fazer"” (BERMAN, 2007, p. 14).

Na terceira parte do livro, intitulado "Los Angeles", o filho da personagem já nasceu, nomeado $\mathrm{C}$, e eles seguem vivendo na cidade do Rio de Janeiro. Já separada de $\mathrm{M}$, ela narra, em poucas páginas, os primeiros anos de vida da criança. 0 foco da narrativa passa a ser o fato dela agora ser mãe e estar envolvida em outras buscas, que não dizem mais respeito só a ela, mas ao filho também: "sem olhar para mim diz: 'Mãe, eu quero ir para algum lugar'. 'A gente está indo para casa', respondo. 'Não, mãe, eu quero ir para outro lugar'. 'A casa do seu pai?', pergunto. 'Não, outro lugar', ele repete. 'Que lugar?'. 'Algum lugar'” (VIDAL, 2009, p. 159). 
Diante da solicitação do filho e da insistência da mãe para que ambos fossem visitar Buenos Aires, argumentando que já era hora do menino conhecer a cidade dos bisavós e da filha lhe ser reapresentada, ela resolve aceitar, não sem alguma hesitação. E a apresentação e a reapresentação fluem de maneira tranquila, porém segue sendo comparativa: “Agora, andando por lugares aos quais tantas vezes fazia referência, é como se visse tudo espelhado: de um lado, Buenos Aires, do outro, o Rio, complementares, uma inexistente sem a outra" (VIDAL, 2009, p. 167-168).

Nesse momento, ao presenciar a mãe comparando as duas cidades, ela percebe que não há tanta diferença assim entre as cidades modernas. Diante do filho deslumbrado com tudo que vê, ela ouve a mãe falando de tudo que mudou e do que permanece, que mais permanências do que mudanças formam a paisagem de Buenos Aires. Não obstante os laços familiares existentes, sua sensação não é de identidade, mas de deslocamento, tal como o que sentira em Los Angeles.

Nesse ponto, é relevante mencionar que a autora e a narradora têm em comum o fato de serem marcadas pelo hibridismo cultural e pelo sentimento de deslocamento. A autora que, tanto em entrevistas quanto na sua obra literária, sempre remete a esse "contínuo estar em trânsito", ao se identificar como brasileira e argentina, integrando, assim, esses dois universos culturais tão distintos, mostra que esse estranhamento é um sentimento característico da sociedade globalizada contemporânea, conforme corroboram as palavras de Said, ao ponderar que:

O exilado sabe que, num mundo secular e contingente, as pátrias são sempre provisórias. Fronteiras e barreiras que nos fecham na segurança de um território familiar, também podem se tornar prisões e são, com frequência, defendidas para além da razão ou da necessidade. 0 exilado atravessa fronteiras e rompe barreiras do pensamento e da experiência. (SAID, 2003, p. 58)

É em Buenos Aires que se passa o último registro desse diário de 170 páginas: mãe e filho resolvem fazer um passeio ao "único cinema da avenida Corrientes: o Los Angeles. Perfeito, penso" (VIDAL, 2009, p. 169).

Berman, citando Kierkegaard, acredita que "a mais profunda seriedade moderna deva expressar-se através da ironia” (BERMAN, 2007, p. 22). Nas últimas páginas do romance, cujo final ficará aberto, "Los Angeles” permanece como algo a ser descoberto, reconhecido, e ressurge, ironicamente, proporcionando um momento de ficção numa 
cidade onde mãe e filho seguirão em busca de sentido para as suas trajetórias nômades. Maffesoli (2001) concebe a viagem como uma contínua iniciação. Nessa perspectiva, a errância "dá ênfase a vida em seu perpétuo recomeço, uma vida sempre e outra vez antiga e atual" (2001, p. 107). Por isso, a liberdade do errante é de quem busca a experiência do ser já que o não pertencimento a um lugar, como é o caso da protagonista não nomeada do romance, cuja trajetória não se fecha, colocando em relevo seu contínuo deslocamento, surge como condição para uma possível construção de si.

Algum Lugar se configura, portanto, como uma narrativa migrante atravessada por experiências de exílio, errância e flâneurie, o que incide em desacertos identitários e desencontros afetivos. Nesse sentido, a autoconsciência da personagem se expressa por meio de uma memória capaz de redimensionar a experiência feminina nômade no cenário contemporâneo.

\section{Referências}

ALMEIDA, Sandra Regina Goulart. Mulheres tão diferentes que éramos: a escritora contemporânea e as narrativas cosmopolitas na aldeia global. In: DALCASTAGNÉ, Regina; LEAL, Virgínia Maria Vasconcelos (Orgs.). Deslocamentos de gênero na narrativa brasileira contemporânea. São Paulo: Horizonte, 2010. p. 12-22.

AUGÉ, Marc. Não-Lugares: Introdução a uma antropologia da supermodernidade. Tradução de Maria Lúcia Pereira. 5. ed. Campinas: Papirus, 2005.

BAUMAN, Zygmunt. $O$ mal estar na pós-modernidade. Tradução de Mauro Gama e Claudia Martinelli Gama. Rio de Janeiro: Zahar, 1998.

BAUMAN, Zygmunt. Modernidade líquida. Tradução de Plínio Dentzien. Rio de Janeiro: Zahar, 2001.

BENJAMIN, Walter. Rua de mão única. Tradução de Rubens R. Torres Filho e José C. M. Barbosa. São Paulo: Brasiliense, 1987. [Obras Escolhidas. v. 2]

BENJAMIN, Walter. 0 narrador. In: BENJAMIN, Walter. Magia e técnica, arte e política: ensaios sobre literatura e história da cultura. 2. ed. Tradução de Sérgio Paulo Rouanet. São Paulo: Brasiliense, 1986. [Obras Escolhidas. v. 1]

BERMAN, Marshall. Tudo que é sólido desmancha no ar: a aventura da modernidade. Tradução de Carlos F. Moisés e Ana Maria L. Ioriatti. São Paulo: Companhia das Letras, 2007. 
CHIARELLI, Stefania. Vidas em trânsito: as ficções de Samuel Rawet e Milton Hatoum. São Paulo: Annablume, 2007.

GHETI, Bruno. Memória e origens voltam a tematizar obra de Paloma Vidal. 2012. Disponível em: http://www.saraivaconteudo.com.br/Entrevistas/Post/46502 Acesso em: 25 fev. 2014.

HALL, Stuart. Da Diáspora: Identidades e Mediações Culturais. Tradução de Adelaide Resende. Belo Horizonte: UFMG, 2003.

MAFFESOLI, Michel. Sobre o nomadismo: vagabundagens pós-modernas. Tradução de Marcos de Castro. Rio de Janeiro: Record, 2001.

REMÉDIOS, Maria Luiza Ritzel (Org.). Literatura confessional: autobiografia e ficcionalidade. Porto Alegre: Mercado Aberto, 1997.

RESENDE, Beatriz Vieira de. Paisagens sem drama. [Publicado originalmente em Jornal 0 Globo, Caderno Prosa e Verso, jan. 2011.] Disponível em: http://www.pacc.ufrj.br/literatura/livros/paisagens-sem-drama.php Acesso em 12 dez. 2012.

RIAUDEL, Michel. Quando a ficção se recorda, quando o sentido passa a resistir. Novos Estudos, 84, p. 251-261, jul 2009. Disponível em: http://www.scielo.br/pdf/nec/n84/n84a14.pdf Acesso em: 20 jan. 2014.

SAID, Edward. Reflexões sobre o exílio e outros ensaios. Tradução de Pedro Maia Soares. São Paulo: Companhia das Letras, 2003.

VIDAL, Paloma. Algum Lugar. Rio de Janeiro: 7Letras, 2009.

Recebido em março de 2014.

Aceito em julho de 2014. 